\title{
A pilot study to assess the possible methods of determining the burden of obstructive sleep apnoea syndrome in primary care
}

\author{
E.L. Palmer ${ }^{a}$, D. Wingfield ${ }^{b}$, K. Jamrozik ${ }^{a}$, M.R. Partridge ${ }^{a, *}$ \\ a Faculty of Medicine, Imperial College London, NHLI at Charing Cross Hospital, \\ St Dunstans Road, London W6 8RP, UK \\ ${ }^{\mathrm{b}}$ Brook Green Medical Centre, London W6 7EG, UK
}

Received 29 October 2004; accepted 17 December 2004

\begin{abstract}
KEYWORDS
Obstructive sleep apnoea;

Screening;

Primary care;

Epworth

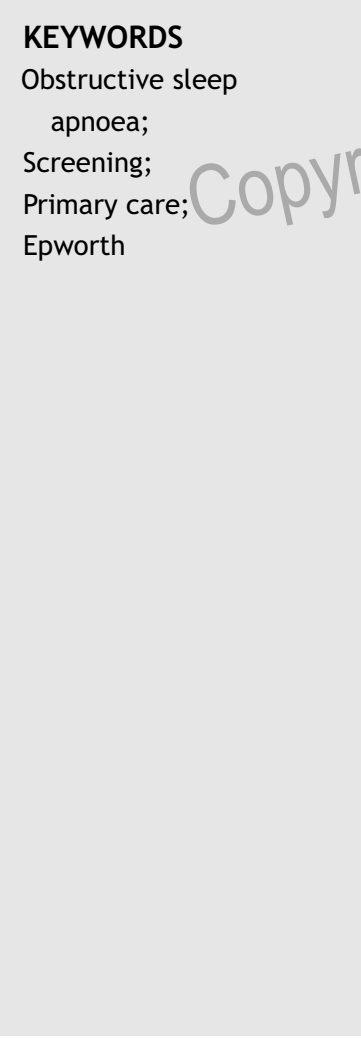

\section{Summary}

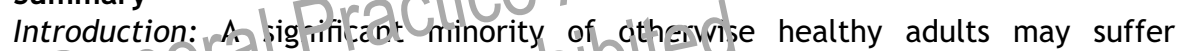
from ai: Orened breathing during $s \in \in$. The commonest problem, known as Obstructive Sleep Aprióa Sy d orne (OSAS), results in poor quality sleep, daytime hyperscannictence and excess risk of road traffic crashes. It is also associated with ec =upational injuries. OSAS can be successfully treated, reducing costs of hospitalisation. There is a gap in the literature regarding the burden of patients with OSAS in primary care, particularly because there is no agreed method for screening. Objectives: This pilot study was designed to determine the feasibility of screening for OSAS in a UK inner-city multi-ethnic primary care population, to investigate ways in which it might be detected, and to gain an awareness of the potential size of the burden of OSAS

Methods: We tested two methods of screening: firstly, postal questionnaires to a random sample of 240 patients from a subset of the population at highest risk of OSAS (men aged 35-65 years); and secondly, the same questionnaire plus two screening tools for detecting hypersomnolence, given to patients attending the practice for pre-registration health checks.

Results: Despite reminders, only $40 \%$ of postal questionnaires were returned and there were only $67(28 \%)$ usable responses. The prevalence of snoring was $55 \%$. Almost half of those patients who responded (46\%) had a Body Mass Index (BMI) associated with a high risk of OSAS. This was not a positive responder bias because there were no significant differences in BMI between responders and non-responders. $12 \%$ had a collar size of greater than 17.5 , whilst $34 \%$ reported daytime sleepiness, and $24 \%$ reported witnessed apnoea.

Screening during pre-registration health checks proved both feasible and productive with 38 patients of differing linguistic abilities completing the assessment.
\end{abstract}

\footnotetext{
* Corresponding author. Tel.: +44 208846 7181; fax: +44 2088467999.

E-mail address: m.partridge@imperial.ac.uk (M.R. Partridge).
} 
Conclusion: Screening for OSAS in primary care by means of a postal questionnaire produced a low response. Whilst there was no evidence of a responder bias in terms of $\mathrm{BMI}$, the numbers reporting large collar size, daytime sleepiness and witnessed apnoea suggest that a sizeable proportion of the population is at risk of OSAS. Questionnaires used in this study provide a means of identifying patients with symptoms suggestive of OSAS, although the sensitivity, specificity and positive predictive value of a selfadministered instrument needs to be confirmed by a larger study incorporating ventilatory monitoring during sleep. The addition of screening to pre-registration health checks is feasible, but it would take a long time to screen all those at risk for OSAS by this route.

(C) 2005 General Practice Airways Group. Published by Elsevier Ltd. All rights reserved.

\section{Introduction}

A narrow collapsible upper airway provides the pathophysiological basis for obstructive sleep apnoea syndrome (OSAS). When the individual is awake this usually causes no problems. During sleep the loss of skeletal muscle tone makes the upper airway narrower and floppier, particularly during rapid eye movement (REM) sleep when muscle relaxation is especially profound [1]. Partial narrowing on inspiration results in turbulent airflow patterns and snoring, whereas occlusion results in apnoea. Until sleep is interrupted and muscle tone is returned, apncea teactob trypoxia and progressively $/ \mathrm{r}$ or $=$ h treriuous respiratery efforts. The consecuent aroisols ans' fiten brief; sleep will recommence after a selv breaths, the airway muscles will relax and the cycle will begin again. Continual disturbance of sleep causes severe sleepiness during daytime. Certain types of body habitus of congenital or acquired origin, including obesity, predispose to the condition $[2,3]$.

OSAS is associated with conditions that account for leading causes of mortality in adults: hypertension, cardiovascular and cerebrovascular disease [4-6]. In addition, daytime sleepiness and impaired cognitive function, symptoms that are linked with OSAS, are of potentially great public health and economic importance, not least through their contribution to motor vehicle crashes and occupational injuries [7].

Current research indicates that making the diagnosis of OSAS in general practice would be worthwhile and cost-effective. Features of OSAS have often been present for some time before patients are referred to sleep services. In a series of 155 patients being treated for OSAS, 84\% reported that excessive daytime sleepiness had been present for a median of eight years prior to diagnosis, and in $80 \%$ a bed partner had witnessed apnoea for a similar time before diagnosis [8]. Canadian studies reveal that in the two years preceding diagnosis, patients with OSAS have a higher than average use of health services and a significantly increased need for treatment of heart and vascular disorders $[9,10]$. Nasal continuous positive airway pressure (CPAP) is an effective treatment for OSAS, and is associated with reduced blood pressure especially in patients taking blood pressure medication [11], increased quality of life [12] (reduced daytime sleepiness and improved alertness [13]), and a reduction in the rate of rald traific crashes [14]. Furthermore? Nviide a road traffic crashes alone vidillo make treatment of OSAS decidedly cost effective singe tinere would be a 12.3-fold return orinives trnent [15]. Hospitalisation costs could also be decreased [16].

Currently, there is a gap in the literature regarding the burden of OSAS in primary care because there is no agreed and effective screening tool. The Berlin questionnaire has recently been used in the USA, Germany and Spain [17] but not in the UK. The participants were individuals attending primary care facilities during a defined period and there was no validation of results.

The present study was designed to investigate ways in which the burden of OSAS in a multi-cultural inner city general practice might be detected, and to determine the feasibility of screening for OSAS in primary care.

\section{Methods}

The study was undertaken at a fully-computerised inner city general practice in Hammersmith, West London.

For this pilot study it was decided to use a postal questionnaire in preference to alternatives such as face-to-face or telephone interviews. This was because self-completed questionnaires could be distributed in large quantities at the same time, for relatively little cost. 
This part of London is multicultural, with over 40 different racial groups and no predominant non-English language, but translation of the questionnaire into numerous languages was not undertaken due to cost constraints. The area's largest ethnic group is White $(77.8 \%)$ and the largest minority groups are Black Caribbeans (5.2\%) and Black Africans (4.9\%). A third (33.6\%) of the resident population was born outside the UK [18].

The pilot screening tool, a self-completed questionnaire, was an adapted compilation of the instrument used by Enright et al., [19] the Berlin Questionnaire [20] and The Sleep Heart Health Study Questionnaire [21] (see Appendix 1). The items sought a history of any features of OSAS such as snoring, excessive sleepiness, and witnessed apnoeas during sleep, as well as details of the participant's driving status and co-morbidity such as high blood pressure. A copy of the Epworth Sleepiness Score [22] was incorporated to quantify sleepiness. This scale asks the participant to rate their chance of falling asleep in eight common situations. The range of possible scores is $0-24$, with scores above 12 regarded as indicating excessive sleepiness.

The highest risk group for OSAS (males aged 35-65 years) was chosen as the post $x i$ questionnaire study population [23-25]. ['detents who had known OSAS, and those -onsidered unable to co-operate on to give informed consent: (di Ge to severe psyciniat ric illness or Froicund learning difficulties, were excluded. The initial survey involved a random sample of 120 patients (5\% of males in the target age range), selected using the practice's computerised database. These patients were sent the self-completed questionnaire together with a covering letter signed by their general practitioner (GP), an information sheet, consent form, and a reply-paid envelope. A postal reminder letter and questionnaire were sent to non-respondents two weeks after the first mailing.

A low response to this first mailing and a high percentage of mail returned as undeliverable, led to a review of relevant records in the practice. This revealed low consultation rates and incomplete records for a proportion of the non-respondents and led to a second random sample of 120 patients being selected. This batch was chosen with the extra inclusion criterion that patients had to have attended a consultation at least once in the last seven years, hopefully eliminating 'ghost patients' and those who had not notified the practice about a change in residence. This second sample of patients was sent the same initial postal package and, two weeks after mailing, non-respondents again were sent a reminder.
Upon return, quantitative data from respondents' answers were coded and entered into a computer database. Each participant's Epworth Score was derived, and body mass index (BMI) was calculated for each participant from his self reported height and weight. Descriptive analyses of response, demographic details, co-morbidity, symptoms of OSAS, driving history and sleepiness scores, were then undertaken using the SPSS software, version 11.5. Data on respondents' BMI were compared with those contained in the practice records of non-responders.

For the second part of the study, the feasibility of adding screening tools and research questions to pre-registration health checks was assessed. Staff members were asked to inform patients about the research study and to inquire if they would be happy to participate. They were then to offer the patients a new pictorial Epworth Sleepiness Scale (The Charing Cross Pictorial Epworth) using structured instructions and, at the end of the consultation, to offer the written questionnaire used in the postal research which included the traditional written EFvorth Scale. Prior studies of patients att enind ing hospital services had shown obod dorcelation between two versions prith 6 Fworth scale, but further validation in a multiculturat: prirnatecare setting was needed. The que:t $t$ jondire was to be completed in reception and hiancled back to staff before leaving the surgery. The person conducting the pre-registration health check was also asked to evaluate how patients reacted to the research, and was asked to give their own views on how the research had been integrated into the everyday routine of the practice.

Quantitative data from the in-practice questionnaire were analysed using the same methods as employed for the postal tool.

The Riverside Research Ethics Committee approved the protocol for the study.

\section{Results}

\section{Results of the postal survey}

Comparison of response to the first $(n=120)$ and second $(n=120)$ sets of postal questionnaires showed no statistically significant differences in demographic characteristics nor frequency of consultation in 2003, despite the minor amendment in the sampling technique. In addition, the proportions of valid responses ( $22 \%$ vs. $34 \%)$, letters returned as undeliverable ( $13 \%$ vs. $6 \%)$ and non-response $(62 \%$ vs. $58 \%)$ were broadly similar. 


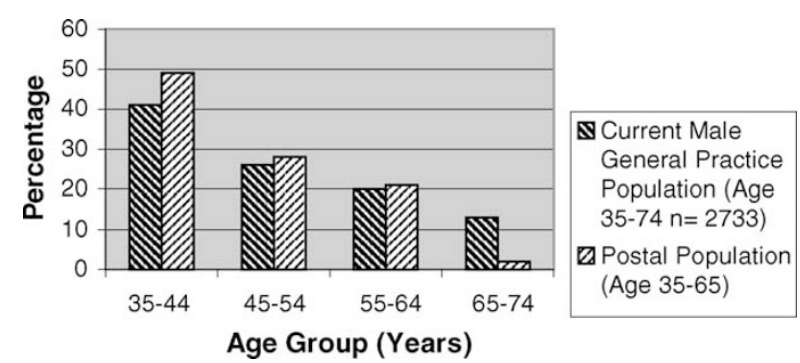

Figure 1 Comparison of age groups within the general practice and postal survey populations.

Therefore, these results are presented as a single sample of 240 adult males aged 35-65 years.

Where possible, demographic data were collected from the general practice computerised database. The arithmetic mean $( \pm$ standard deviation (SD)) age was 46.8 ( \pm 8.6 years), with a mode of 39 years. This random study sample was considered representative of the practice population of male patients in relation to age (see Fig. 1). Additionally, this pattern accords with local census information [26].

Information regarding ethnicity of the 240 patients was incomplete, with $39 \%(n=94)$ not having this information recorded in their medical record. Of the 146 recorded ethnic origins, the highest proportion were W/hite $(51 \% 2)=122)$ followed by Black or Black Eriiis $(4.6 \% n=11)$, Asian $(2.9 \%(n=7)$, atric oy er or mixed ethrit: origias $(2.6 \% n=6)$. As ethnicity data $\cdots \in$ incoinplete for the whole practice population, it was not possible to make comparisons with the study sample.

Practice records of BMI for responders and nonresponders showed a mean BMI for responders of 26.5 (SD 5.9) in the 66 patients for whom data were recorded, and a mean BMI of 26.0 (SD 4.3) in 108 non-responders for whom data were available. The mean BMI derived from the completed questionnaires was 25.7 (SD 4.2). As this comparison indicates that there was no significant responder bias, the rest of the interpretation and discussion is based upon self-reported BMI.

\section{Analysis of completed postal questionnaires}

Overall there was a response rate of $28 \%(n=67)$, plus a further 23 questionnaires (10\%) which were returned as undeliverable, and five (2\%) which were returned with participation consent refused. The age range of the patients returning usable questionnaires was 35-64 years with a mean (SD) of $49.2(8.0)$ years and a mode age of 47 . The ethnic origins of these patients were principally White $(n=56)$, and the remaining patients were of Asian $(n=6)$, Black $(n=2)$ and Mixed $(n=1)$ ethnic origins. Two patients failed to report their ethnic origins.
Body mass index (BMI) could be calculated for 64 patients and ranged from $19-38 \mathrm{~kg} / \mathrm{m}^{2}$ with a mean BMI (SD) of $25.7(4.2) \mathrm{kg} / \mathrm{m}^{2}$. Using Bray's criteria [27], one patient was underweight, 32 were in the acceptable weight range for height, 24 would be considered overweight, and seven patients were obese.

Of the patients who completed the questionnaire, $58(87 \%)$ reported their collar size. Reported collar sizes ranged from 14-20 inches, with seven (12\%) having a collar size of 17.5 or more.

Sixty-five participants answered the questions on their driving status and history. Analysis revealed 35 participants held a single ordinary licence, and three participants held two licences. Eight participants reported that they had had at least one road crash in the last 5 years. One of these, a patient aged 62 years, reported that he drove almost every day of the week and that he held two licences (motorbike and ordinary). He had positive responses for snoring, cessation of breathing during sleep and daytime sleepiness, a collar size of 16 and an Epworth Srore of $\%$ Three of the other patients who had hac crasiries held ordinary licences, crbve al most every day of the week, and reported snoring and Epworth scores ranging from 6-10. The ren riiting four patients did not report ariy) S, mptoms of OSAS, but one had an Epworth score of 15.

With regard to other symptoms associated with possible sleep apnoea (Fig. 2):

- Complaints about loud snoring were reported by 37 participants $(55 \%)$, with a median time since the first recalled report of snoring of 10 years, a range of $1-32$ years (2003-1972) and an interquartile range (IQR) of 5-14 years.

- 16 patients $(24 \%)$ reported that someone had told them that, whilst asleep, there were times when they stopped breathing for a while, then snored and snorted loudly. The median time since the first recalled report of breathing cessation was 5 years (range: $0-31$ years; IQR: $2-12$ years).

- Daytime sleepiness was recorded by 23 participants $(34 \%)$. The range of time since these periods of sleepiness started was 1-39 years (median: 8 years; IQR: 4-10 years).

Scores for the Epworth Scale were available for 64 of the 67 participants, and ranged from 0 to 24. The median score was 4 out of 24 (IQR: 2-8). The highest Epworth Scores were 24, 20, and 15; participants gaining scores of 24 and 20 are described below. The participant with a score of 15 reported no symptoms of OSAS but did report a crash while driving in the last 5 years. 


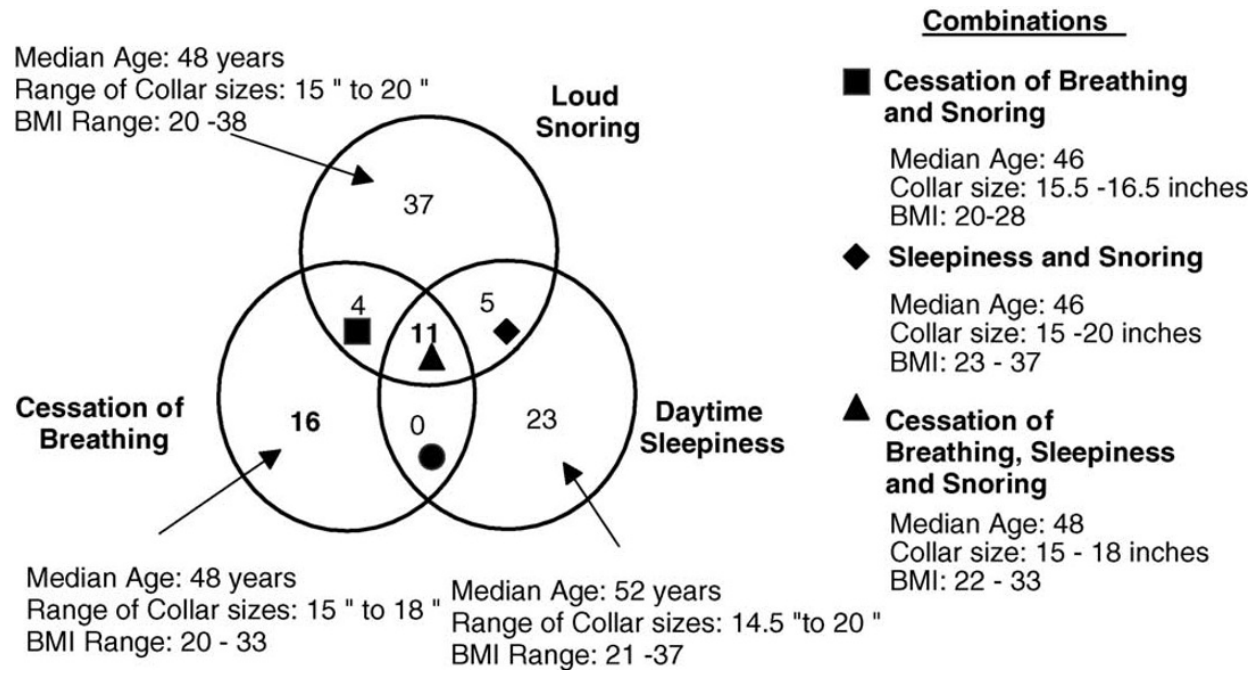

Figure 2 Features of possible sleep apnoea reported by postal survey participants.

There was only one patient with a combination of snoring, cessation of breathing during sleep, daytime sleepiness and a high Epworth score. This patient was aged 35 years, had no knowledge of his collar size, had a 'normal' BMI of $22 \mathrm{~kg} / \mathrm{m}^{2}$ and an Epworth score of 20.

Another patient aged 55, with a very hisn Epworth score of 24, reported sympter t.5 of sating and daytime sleepiness $t_{\mathrm{a}} \mathrm{n}$ a $3 \mathrm{~m}$ of $37 \mathrm{~kg} / \mathrm{m}^{2}$ which is in the bese ange a colla sizel of 17.5 inches, and had nocturia th $\in \in \in$ ti ries a night.

\section{Pre-registration health checks}

During the study period, 45 new patients $(23$ male, 22 female) completed pre-registration health checks at the practice. They were aged between 18 and 54 years, with a mean age (SD) of 28 (6.9) years (see Fig. 3), and $34(76 \%)$ of them were white.

Of the patients who completed a health check, 38 answered both the Charing Cross Pictorial Epworth Scale and the written screening tool. Four patients completed only the Pictorial Epworth scale; two of these had 'no time' and one had

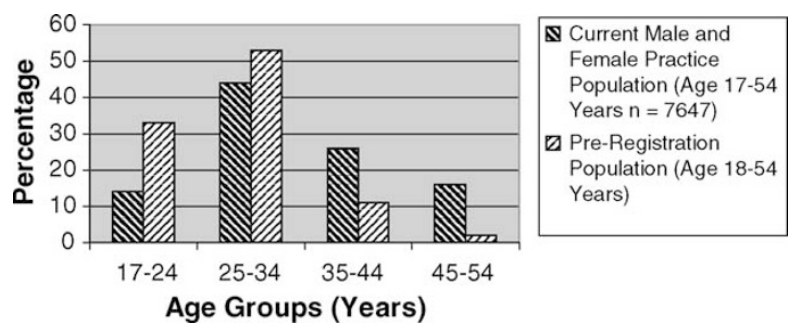

Figure 3 Comparison of age groups within the general practice and pre-registration populations. no comprehension of English. The final patient's slight understanding of English meant that after partial translation she was able to complete the Pictorial Scale but found the malority of the written document $\mathrm{tog}$ Sifficult to comprehend. Two patien - V/ere tor unwell to complete both - Ereening tools ans one patient refused to participat $=$ in th $\mathrm{e}$ study.

\section{Screening tool results in those attending for pre-registration health checks}

The mean (SD) BMI of these 45 patients was 23.7 (3.7) $\mathrm{kg} / \mathrm{m}^{2}$. Again, using the standard interpretations of BMI [27], one male patient and five female patients were underweight, 12 male patients and 10 female patients were in the normal weight range, five male and five female patients were overweight, and one patient was obese.

Of the 19 male patients who answered the selfcompleted screening tool, only 10 had knowledge of their collar size (range 15-17.5 inches). Features suggestive of possible OSAS, such as witnessed apnoea, snoring, sleepiness and high BMI, found in those attending pre registration health checks, are shown in Fig. 4.

Scores for the Traditional Epworth Scale ranged from 1-17 with a median score of 6.5 out of 24 and the Charing Cross Pictorial Epworth scores ranged from $0-14$. Significant hypersomnolence is usually regarded as an Epworth score of 10 or more. The highest Epworth scores recorded were by a female who scored 17 and 14 in the Traditional and Pictorial scales, respectively. This patient also reported daytime sleepiness in the self-completed screening tool but no other symptoms. 


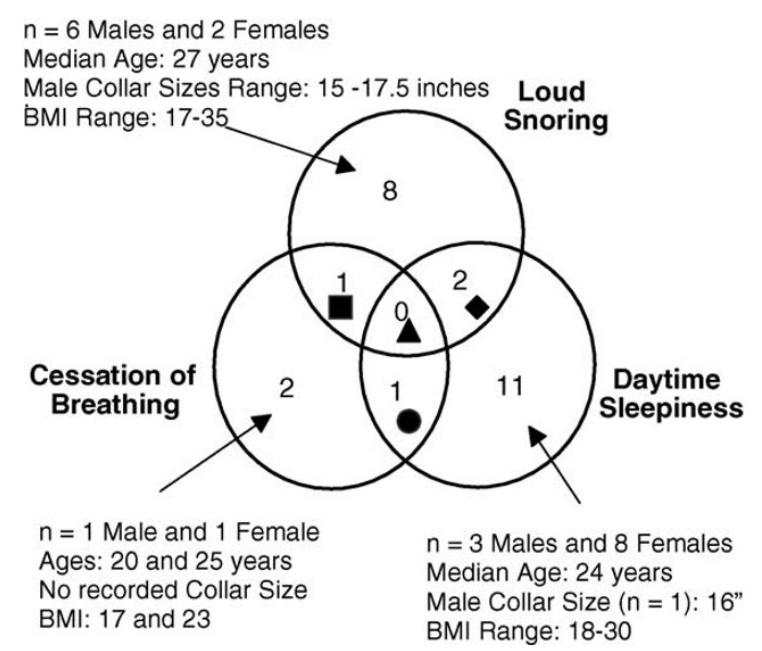

Combinations

Cessation of Breathing and Snoring

$\mathrm{n}=1$ Female

Age: 25 years

BMI: 17

Sleepiness and Snoring

$\mathrm{n}=1$ Male and 1 Female Ages: 28 and 24 years Male Collar size: 16 inches BMI: 27 and 29

Cessation breathing and sleepiness $\mathrm{n}=1$ Male, Age 20 years No Collar Size Recorded BMI: 23

Figure 4 Features of possible sleep apnoea reported in pre-registration health checks.

\section{Discussion}

Services for the diagnosis and management of OSAS are frequently under-resourced, and their availability is patchy. However, evidence exists of delays in diagnosis, and resultant suffering and excessive use of other resources [8-10]. Earlier referral for diagnosis of those most atzisk of OSAS would seem to be sensite Whithet this should invoive fornt al : Creening of the nopulation, public awareness campaigns, or ari) roved nealth professional understanding of the condition, is unclear.

In this study, postal questionnaire screening to determine the likely burden of OSAS in a multicultural inner city general practice resulted in only $28 \%$ usable responses. Only one questionnaire from the postal survey was answered inadequately because of limited comprehension of English, but we cannot judge whether similar problems contributed to the low overall response. Lack of facility in English was a reason for non-completion in two patients undergoing pre-registration health checks. In larger studies, this could potentially be overcome through translation, provided the general practice had a record of each patient's preferred language.

Whilst the participants in the postal survey were demographically representative, the low response may have introduced a positive responder bias, leading to over-estimation of features suggestive of OSAS. Though our data on BMI militate against positive responder-bias amongst those morphologically at risk of OSAS, there could still be responder bias amongst those who snore. This could be a reason for our relatively high snoring prevalence of $55 \%$, this being higher than the usually quoted prevalence of $40 \%$. Previous studies in primary care have shown response rates of $50-60 \%[28,29.30]$. Onc postal survey of satisfaction with the $i \mathrm{HS}$ anongst patients randomly seredted iforn general practices in the bor ough of Hammersmith and Fulham recorded a respons ra of 29\% [31]. The Cochrane Ditt:base ol Methodology [32] has reported that the most effective approaches for increasing response to postal questionnaires are recorded delivery and monetary incentives. Both telephone and postal reminders also increase response $[29,33]$. Undeliverable mail contributed to our low response. Patients who change address without notifying their doctor are an acknowledged problem within primary care, and potentially limit screening programmes run from general practice.

Out of those who responded, $46 \%$ had a BMI that might suggest higher risk of OSAS, $12 \%$ had a collar size greater than 17.5 , and $24 \%$ reported witnessed apnoea. The prevalence of snoring was much higher at $55 \%$. One third of respondents (34\%) reported what might be interpreted as excessive sleepiness. A number of individuals had combinations of these symptoms: for example, 11 respondents $(16 \%)$ reported witnessed cessation of breathing, sleepiness and snoring; and nine reported snoring, either with witnessed apnoea or sleepiness. The results suggest that a sizeable proportion of the population might be at risk of OSAS.

As an alternative to a postal survey, detection of excessive daytime sleepiness (a key feature of OSAS) via pre-registration health checks, using two 
different sleepiness-screening tools and the written questionnaire, proved feasible and productive. 38 patients completed both sleepiness scales, with the majority $(71 \%)$ having no problems understanding them. $21 \%$ of patients who completed the written screening tool had been told that they snore loudly, while $5 \%$ reported witnessed apnoea. Daytime sleepiness was reported by $29 \%$ of patients, although the Epworth scale indicated that only one of these patients had what might be regarded as excessive sleepiness. However, the age profile of those attending for pre-registration health checks was skewed toward younger age groups, where the risk of OSAS is low. Discussions with general practice staff and evaluation of appraisal sheets revealed that implementation of screening via pre-registration health checks was well accepted, with noteworthy surprise as to how little disruption the 'research' caused to daily routines. Staff who participated in the recruitment of new patients and collection of data during health checks found the project both interesting and educational, and the reactions of patients were similarly encouraging.

Despite the addition of OSAS screening questions to pre-registration health checks proving feasible and acceptable to patients, those undergoing sucii checks are often younger than thoseffidents most at risk of OSAS. hdininis:ration of the questionnaires use din this urvev (when valic dt=d) to all males between the ages of $3:-6$. the surgery for any reason is a possible alternative strategy - but males of this age group consult less frequently than any other group, and opportunistic administration of a questionnaire is likely to miss a large proportion of the population at risk.

The screening questionnaire used in this study now needs to be further refined and validated, by undertaking sleep studies in patients with and without features suggestive of OSAS, in order to determine its sensitivity and specificity. A recent US study suggests that sleep studies using overnight oximetry alone may be sufficient in this context [34]. However, research into the condition is undersupported [35], and validation of a screening questionnaire would place further pressures on limited diagnostic services. Nevertheless, once validated, such tools may permit a focused attempt to screen for the condition amongst those more likely to have it (for example the obese or hypertensive), or amongst those at greater risk of consequences from non-treatment (for example, commercial drivers). In parallel with attempts to improve instruments and protocols for screening, there is a need for greater public and health professional awareness of OSAS, if the condition is to be recognised and treated more promptly.

Acknowledsmitot

- this work could not have been carried out without the kind cooperation of Miss Ramesh Ghiassi, Clinical Scientist, Sleep Laboratory, Charing Cross Hospital. 


\section{Appendix 1}

\section{APPENDIX}

Sleep Apnoea Questionnaire One - 2004

Emis $\mathrm{N}^{\mathrm{e}} \mathrm{\square} \square \square \square$

Date: $\ldots . . / \ldots / \ldots$

\begin{tabular}{|l|l|}
\hline & \\
\hline Q.1 & Please complete the following: (please write your answers) \\
& 1. Height ................Feet and inches/ metres \\
& 2. Sex Male/Female \\
& 3. Weight ................Stones and pounds/ Kg \\
& 4. Age Years \\
& 5. Ethnicity ...........(If you are unsure please choose from the list \\
at the end of the second questionnaire.)
\end{tabular}

Q.2 Do you know your shirt collar size? (Please circle your answer)

1. Yes -Please answer the question below before Question 3

2. No - Please go to Question 3

If you answered yes, please state your collar size ...........

Q.3 Has anyone ever co mplained that you snore loudly? (Please circle your answer)

1. Yes - Please go to Question 4

2. No - Please go to Question 5

The boxes below are

for staff use only.

Please do not write

in them.

When did someone first comp rain a wit youcloud snoring? (Please write your ansiver)

In. (r um er of year e.g. 1995)

OR ... vears ago ( 8.8 yearisto

Q.5 Has any pne told you that, $w$ hile you are sleeping, there are times when you stopped breathing for a while, then snored and snorted loudly? (Please circle your answer)

1. Yes - Please go to Question 6

2. No - Please go to Question 7

Q.6 When did someone first tell you that you stopped breathing in your sleep? (Please write your answer)

In ..... (number of year e.g. 1995)

OR..... years ago (e.g. 8 years ago)

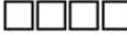

Q.7 Are you usually sleepy in the daytime?

(Please circle your answer)

1. Yes - Please go to Question 8

2. No - Please go to Question 9

Please turn over and complete the remaining questions... 


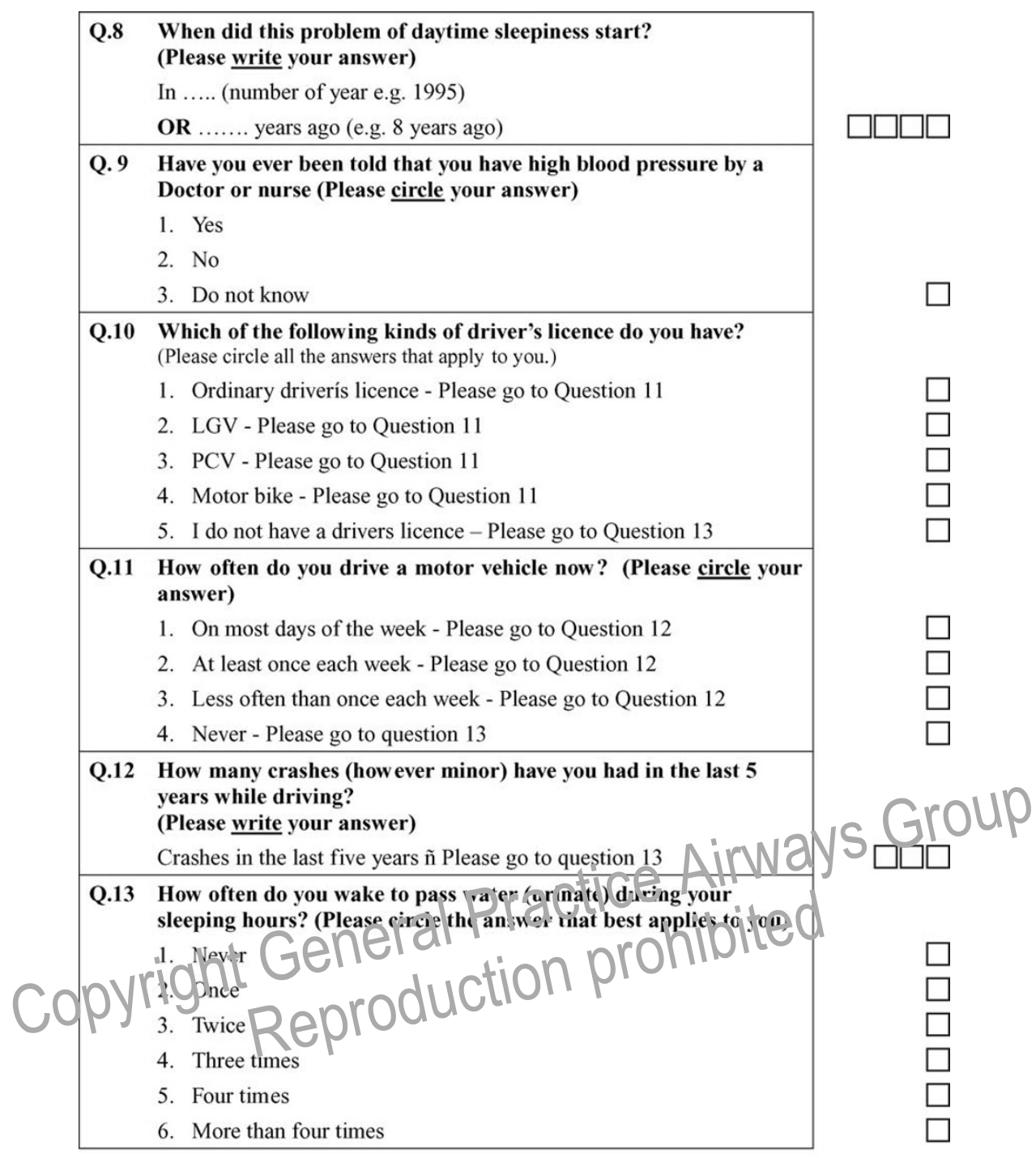

THANK YOU FOR YOUR HELP

You have finished the first questionnaire, now please complete the second questionnaire 


\section{Questionnaire Two.}

In contrast to just feeling tired, how likely are you to doze off or fall asleep in the following situations? Even if you have not done some of these things recently, try to work out how they would affect you. Use the following scale to choose the most appropriate number for each situation.

$$
\begin{aligned}
& 0=\text { no chance of dozing } \\
& 1=\text { slight chance } \\
& 2=\text { moderate chance } \\
& 3=\text { definitely would doze }
\end{aligned}
$$

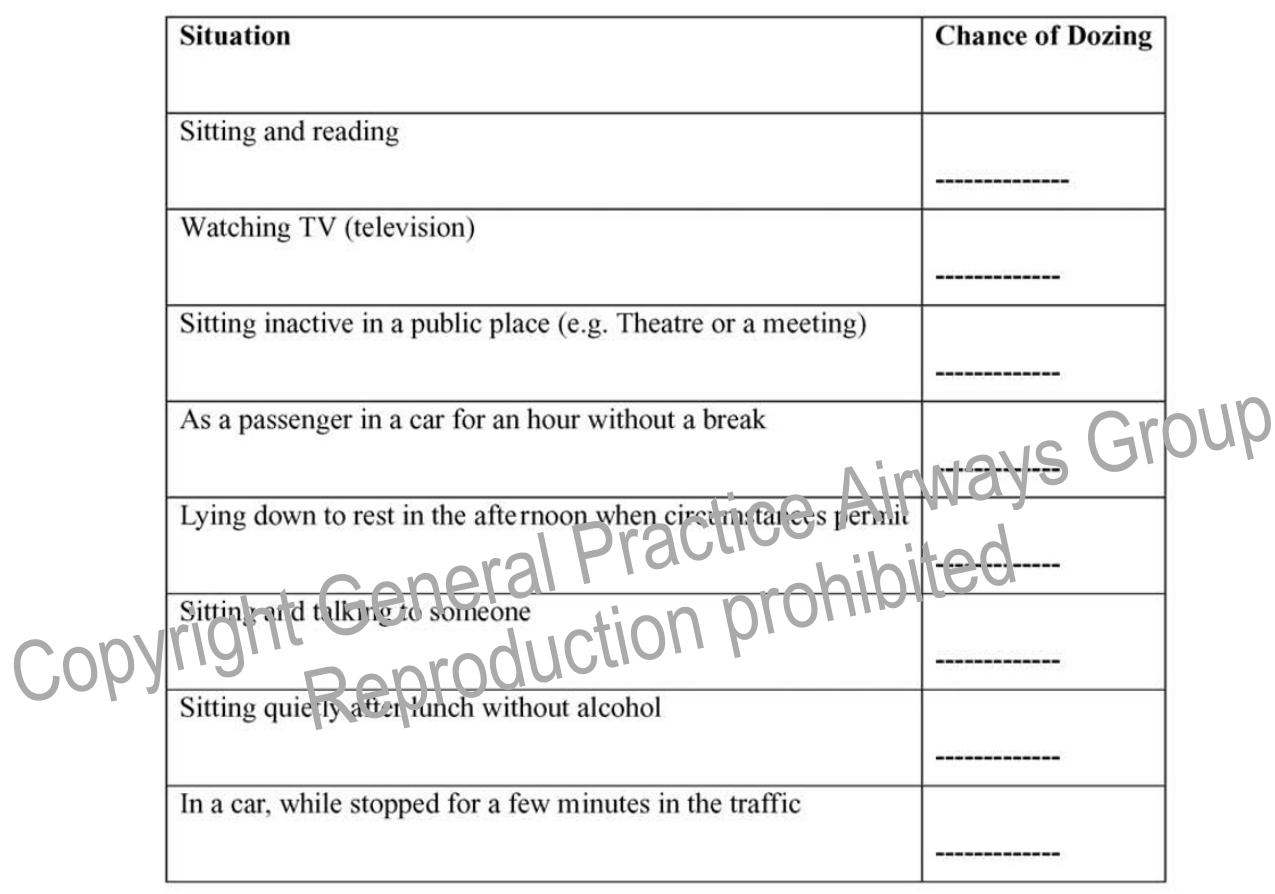

THANK YOU FOR YOUR HELP

You have now finished both questionnaires. Please return both questionnaires to reception or to the person who conducted your pre-registration health check. 


\begin{tabular}{|lll|}
\hline Ethnicity Help List: & & \\
White & Black or Black British & Asian or Asian British \\
White British & Black Caribbean & Indian \\
White Irish & Black African & Pakistani \\
White Other & Black Other & Bangladeshi \\
& & Other Asian \\
Mixed & Other Ethnic Groups & \\
White and Black Caribbean & Chinese & \\
White and Black African & Other Ethnic group & \\
White and Asian & & \\
Mixed & & \\
Other & & \\
\hline
\end{tabular}

\section{References}

[1] Loadsman JA, Hillman DR. Anaesthesia and sleep apnoea. Br J Anaesth 2001;86:254-66.

[2] Grunstein RR, Wilcox I. Sleep-disordered breathing and obesity. Baillieres Clin Endocrinol Metab 1994;8:601-28.

[3] Redline S, Tosteson T, Tishler PV, et al. Studies in the genetics of obstructive sleep apnea. Familial aggregation of symptoms associated with sleep related breathing disturbances. Am Rev Respir Dis 1992;145:440-4.

[4] Hung J, Whitford EG, Parsons RW, Hillman DR. Association. of sleep apnoea with myocardial infarction in men i $a$ anc $c$ 1990;336:261-4.

[5] Mooe T, Rabben T, Wiklund', , F r r rklin WA, Eriksson P. Sleen disordered reat th ins in men with coronarvartery aise Chest 1996; 109:65;-63.

[6] Palomaki H. Snoring and the risk of ischaemic brain infarction. Stroke 1991;22:1021-5.

[7] Leger D. The cost of sleep-related accidents: a report for the National Commission on Sleep Disorders Research. Sleep 1994;17:84-93.

[8] Ghiassi R, Murphy K, Partridge MR. Delays in diagnosis of OSAHS. Thorax 2004;59:540.

[9] Kryger MH, Roos L, Delaive K, Walld R, Horrocks J. Utilization of health care services in patients with severe obstructive sleep apnoea. Sleep 1996;19:S111-6.

[10] Otake K, Delaive K, Walld R, Manfreda J, Kryger MH. Cardiovascular medication use in patients with undiagnosed sleep apnoea. Thorax 2002;57:417-22.

[11] Pepperell JCT, Ramdassingh-Dow S, Crosthwaite N, Mullins $R$, Jenkinson C, Stradling JR. Ambulatory blood pressure after therapeutic and sub-therapeutic nasal continuous positive airway pressure for obstructive sleep apnoea: a randomised parallel trial. Lancet 2002;353:204-10.

[12] Polo O. CPAP for the treatment of sleep apnoea. Lancet 1999;353:2086-7.

[13] Jenkinson C, Davies RJO, Mullins R, Stradling JR. Comparison of therapeutic and sub-therapeutic nasal continuous positive airway pressure for obstructive sleep apnoea: a randomised prospective parallel trial. Lancet 1999;353:2100-5.

[14] Cassel W, Ploch T, Becker C, Dugnus D, Peter JH, von Wichert P. Risk of traffic accidents in patients with sleepdisordered breathing: reduction with nasal CPAP. Eur Respir J 1996;9:2606-11.
[15] Douglas NJ, George CF. Treating sleep apnoea is cost effective. Thorax 2002;57:93.

[16] Bahamman A, Delaive K, Ronald J, et al. Heatlh care utilization in males with obstructive sleep apnoea syndrome two years after diagnosis and treatment. Sleep 1999;22: 740-7.

[17] Netzer NC, Hoegel JJ, Loube D, et al Prevalence of symptoms and risk of sleep ipnea in brinary care. Chest 2003; 124:1406-14:

[18] Naticnal siatist Wetsite. Census 2001: Hammersmith ard Fulham Statistic. www.statistics.gov.uk/census2001 (Accessed ph 13.04.04).

[19] Erright Pl, Newman AB, Wahl PW, et al. Prevalence and crrelates of snoring and observed apnoeas in 5,201 older adults. Sleep 1996;19:531-8.

[20] Netzer NC, Stoohs RA, Netzer CM, Clark K, Strohl KP. Using the Berlin Questionnaire to identify patients at risk for the sleep apnoea syndrome. Ann Intern Med 1999;131:48591.

[21] Young T, Shahar E, Nieto FJ, et al. Predictors of sleep-disordered breathing in community-dwelling adults: The Sleep Heart Health Study. Arch Intern Med 2002;162:893-900.

[22] Johns MW. A new method for measuring daytime sleepiness: the Epworth Sleepiness Scale. Sleep 1991;14:540-5.

[23] Young T, Peppard PE, Gottlieb DJ. Epidemiology of obstructive sleep apnea: a population health perspective. Am J Respir Crit Care Med 2002;165:1217-39.

[24] Peppard PE, Young T, Palta M, Dempsey J, Skatrud J. Longitudinal study of moderate weight change and sleepdisordered breathing. JAMA 2000;284:3015-21.

[25] Stradling JR, Davies RJ. Sleep 1: Obstructive sleep apnoea/hypopnoea syndrome: definitions, epidemiology and natural history. Thorax 2004;59:73-8.

[26] Government Census, 2001. Hammersmith and Fulham Statistics http://www.statistics.gov.uk/census2001/pop2001/ Hammersmith_and_Fulham.asp (Accessed 13.04.04).

[27] Bray GA. Definition, measurement, and classification of the syndromes of obesity. Int J Obese 1978;2:99-112.

[28] Salisbury C. Postal surveys of patients' satisfaction with a general practice out of hours cooperative. BMJ 1997;314:1594-8.

[29] Asch DA, Jedrziewski MK, Christakis NA. Response rates to mail surveys published in medical journals. J Clin Epidemiol 1997;50:1129-36. 
[30] Cummings SM, Savitz LA, Konrad TR. Reported response rates to mailed physician questionnaires. Health Serv Res 2001;35:1347-55.

[31] Hammersmith and Fulham Primary Care Trust Patient Survey. http://www.hfpct.nhs.uk and $\mathrm{CHI}$ website www.chi.gov.uk (accessed on 23.03.04).

[32] NeLH, Cochrane Gems Archive. Increasing response rates to postal questionnaires. http://www.nelh.nhs. uk/cochrane_gems060801.asp (accessed 23.03.04).
[33] Edwards P, Roberts I, Clarke $M$, et al. Increasing response rates to postal questionnaires: systematic review. BMJ 2002;324:1183.

[34] Gurubhagavatula I, Maislin G, Nkwuo JE, Pack Al. Occupational screening for obstructive sleep apnea in commercial drivers. Am J Respir Crit Care Med 2004; 170:371-6.

[35] Rippon I, Lewison G, Partridge MR. Research outputs in respiratory medicine. Thorax 2005;60:63-7.

Available online at www.sciencedirect.com

science@Direct.

Available online at http://www.thepcrj.com

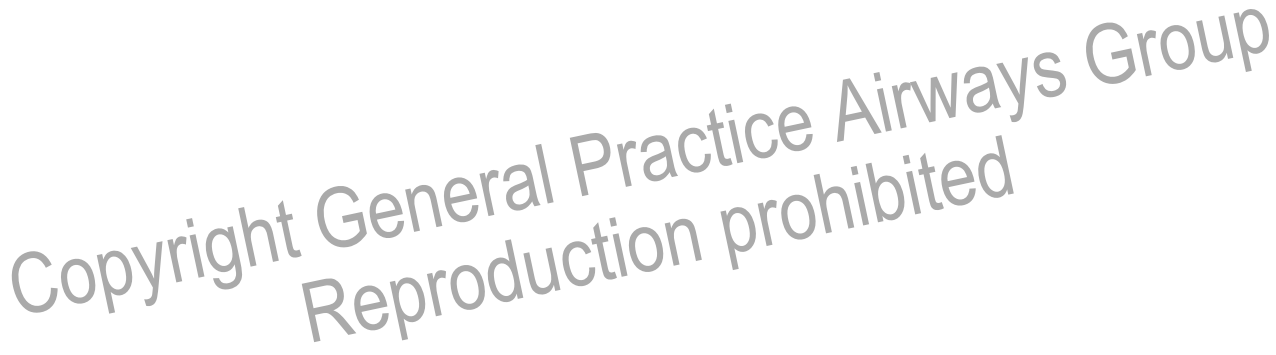

